Portland State University

PDXScholar

\title{
An Update to the Proficiency Benchmarks for Surgical Simulation Training in Laparoscopy at Oregon Health and Science University
}

Caleb Alan Haley

Portland State University

Follow this and additional works at: https://pdxscholar.library.pdx.edu/honorstheses

Let us know how access to this document benefits you.

\section{Recommended Citation}

Haley, Caleb Alan, "An Update to the Proficiency Benchmarks for Surgical Simulation Training in Laparoscopy at Oregon Health and Science University" (2014). University Honors Theses. Paper 99. https://doi.org/10.15760/honors.60

This Thesis is brought to you for free and open access. It has been accepted for inclusion in University Honors Theses by an authorized administrator of PDXScholar. Please contact us if we can make this document more accessible: pdxscholar@pdx.edu. 
An Update to the Proficiency Benchmarks for Surgical Simulation Training in Laparoscopy at Oregon Health and Science University

by

\author{
Caleb Alan Haley
}

An undergraduate honors thesis submitted in partial fulfillment of the requirements for the degree of
Bachelor of Science
in
University Honors
and

Science

Thesis Advisers

Donn Spight, MD, FACS - Oregon Health and Science University Lawrence Wheeler, PhD - Portland State University

\title{
Portland State University
}

in collaboration with Oregon Health and Science University 


\section{Acknowledgements}

I would like to express my sincere appreciation and thanks to my thesis advisers, Dr. Donn Spight of the Oregon Health and Science University Department of Surgery and Dr. Lawrence Wheeler of the Portland State University Honors College. Your guidance and support through this endeavor has been invaluable.

I would also like to thank my team at VirtuOHSU:

Elena An, Patricia Southard, and co-volunteers, especially (future Dr.) William Coad.

Thank you to the Portland State University Honors College as well as the Oregon Health and Science University Department of Surgery for allowing me to embark upon this project.

Lastly, special thanks should be given to my family and friends for supporting me throughout this process, as well as the entirety of my academic life.

Without your love and encouragement over the years, I would not be where I am today. 
"You never change things by fighting the existing reality.

To change something, build a new model that makes the existing model obsolete."

- Richard Buckminster Fuller 


\section{ABSTRACT}

As the field of medicine, especially surgery, progresses, new challenges in the training of physicians have emerged. While surgical education has been traditionally structured as an apprenticeship-based model, this has proven to be time consuming, costly, and unethical to patients, physicians, and medical institutions alike. One solution that has arisen due to the need for balancing safety with education is the usage of simulation-based training. Simulation has become an accepted and valued way of training physicians due to its assurance of safe, scheduled, targeted, and objective training for the learner, as well as safe and efficient clinical experiences for patients.

Oregon Health and Science University (OHSU), along with every other accredited surgical residency program in the United States, has integrated a skills lab into their general surgery curriculum due to a 2008 mandate issued by the Accreditation Council for Graduate Medical Education (ACGME). The surgical simulation skills lab at OHSU is titled VirtuOHSU. A core part of VirtuOHSU's curriculum involves the training of basic laparoscopic skills. As simulation-based training was established, there was not a clear development of a standardized training curriculum for laparoscopic surgery and thus there has been a significant gap in the discourse's understanding of what proficiency metric is considered adequate for laparoscopic surgery training.

In 2008, the OHSU general surgery residency program adopted proficiency levels from a study done by Drs. E. Matt Ritter and Daniel J. Scott of the University of Texas Southwestern Medical Center. For the past six years, VirtuOHSU has used these standards to evaluate their general surgery residents. The goal of this paper was to evaluate the validity 
of the standard used at VirtuOHSU. My research suggests, that due to the arbitrary nature of these standards, the current proficiency benchmarks are not an effective way of evaluating the skill level of surgical residents trained at OHSU.

In July 2014, OHSU's Department of Surgery will adopt the ACGME Milestones Project and moving forward with this project it will be necessary to determine what is acceptable competency standards for laparoscopic surgery training. The results found, in the data collection part of this work, guided the creation of new laparoscopic proficiency benchmarks for each program year level of general surgery residents. In the future, the correlation between simulation skills lab performance and actual operative performance will be examined.

\section{CHALLENGES IN SURGICAL EDUCATION}

It has long been accepted that superior performance is acquired through learning and adaptation. Thus, in a field characterized by superiority, if not total perfection, it is not surprising that understanding this concept is at the forefront of surgical education programs across the country ${ }^{1}$. As the discipline of medicine, especially surgery, evolves, the task of educating the next generation of surgeons is faced with many new and unique challenges.

As physicians start their training in the early days of medical school, this phase of their education is characterized by a broad exposure to the largely diverse field of medicine. In essence, medical school creates physicians that are, "jacks of all trades, masters of none, with limited apprenticeship [opportunities]”2. 
Specialization and in-depth training, within a specific field of medicine, later takes place during a physician's time as a resident via an apprenticeship-based education model. For a surgeon, this apprenticeship-based approach has been traditionally rooted in training and learning taking place directly in a live operating room. However, a trainee's experience as a resident can vary greatly from region to region, hospital to hospital, even resident to resident. This is due to three main factors. First, a resident's experience is determined by the patients (and thus cases) that are seen during his or her time in a residency program. While many conditions are diagnosed and treated often, others are seen only rarely in the apprenticeship phase of a physician's education. Secondly, the skill set of each trainee varies greatly from person to person depending on their educational history and natural abilities. Third, the skill-level of their teachers may greatly differ; while a teacher may be a very capable surgeon, many do not have the skills necessary to be an effective educator, especially while they are simultaneously trying to operate.

Additionally, as the field of medicine grows, there is also an increasingly large amount of material to cover and the apprenticeship model is not able to meet the growing demands. As of a 2003 mandate by the ACGME, residents have been limited to 80-hour workweeks ${ }^{3}$. While this mandate has improved resident quality of life, it has been at a serious cost to the amount of education they are able to receive. Furthermore, after surgeons complete their residency programs, their time for "formal education ends abruptly" and there are "limited opportunities for learning new techniques or re-training" 2 .

Many ethical and fiscal dilemmas are also linked to training new surgeons via an apprenticeship-based model in the operating room. In 1999, a radical report issued by the 
U.S. Institute of Medicine was published titled, "To Err is Human: Building a Safer Health System.” In this report, it was estimated that 44,000 - 98,000 people per year "die in [U.S.] hospitals each year as a result of medical errors that could have been prevented" ${ }^{4}$, many of which stem from the inadequate performance of health care providers including "error in the performance of [surgical] operation $[\mathrm{s}]^{\prime \prime}$. It was also estimated that due to the training of new surgeons, institutions encountered an additional $\$ 50,000$ per surgical trainee over a five-year period due to additional procedure time associated with training in the operating room ${ }^{5}$.

As media coverage $e^{6,7}$ and patient awareness increased, surgical education programs were forced to critically evaluate their ability to train proficient surgeons. It was accepted that there was an ethical obligation to move skill learning away from patients and into a controlled environment whilst balancing education and safety ${ }^{8}$.

\section{SIMULATION IN SURGICAL EDUCATION}

The traditional apprenticeship-based model of teaching in the operating room proved to be time-consuming, costly, and unethical. Thus, a new approach to surgical education, one that ensured uniform and reliable training, was required for the future of general surgery residency programs.

While this problem of using an apprenticeship-based model was gaining a significant amount of scrutiny in the field of surgical education, it was not the only discipline to experience this attention. Other high-risk industries had also undergone this philosophical debate within their discourses; simulation emerged as the answer to a safe and cost-efficient training model for many (most notably in the fields of aviation, aerospace, and nuclear 
power) ${ }^{8,9}$. These industries benefited from simulation by maintaining a uniform culture of safety, using optimal structures and procedures, providing intensive and uniform training, conducting thorough and organizational learning and safety management, and providing immediate feedback ${ }^{2}$; surgical education programs realized they could benefit in the same ways. The idea of training residents outside of the operating room was on the rise ${ }^{10}$.

There are many advantages to simulation in surgical education; for the trainee, this training ensures scheduled, targeted, and objective training and for the patient, this preprocedural training ensures a safe and efficient clinical experience. Simulation in medicine allows for the training, certification, maintenance, and remediation of skills for a variety of healthcare providers. Since 1993 when Richard Satava first proposed the used of virtual reality simulation in surgical education ${ }^{11}$, simulation in surgical training has become accepted as a valuable, valid, and necessary method of training future surgeons ${ }^{12,13}$. In fact, starting in 2008 the Accreditation Council for Graduate Medical Education (ACGME) Resident Review Committee (RRC) started requiring surgical simulation in all accredited surgical residency programs ${ }^{14}$. This requirement catalyzed the creation of a surgical simulation skills lab in the Department of Surgery at Oregon Health and Science University (OHSU).

\section{VIRTUOHSU AT OREGON HEALTH AND SCIENCE UNIVERSITY}

In 2008, the OHSU Department of Surgery opened its doors to a new, state of the art, surgical simulation lab dedicated to "improving healthcare through virtual reality and simulation"15, aptly named VirtuOHSU. As of March 2009, VirtuOHSU received full Level 1 ACS Accreditation as an Education Institute from the American College of Surgeons, 
further establishing VirtuOHSU and the Department of Surgery as a nationally recognized simulation institute ${ }^{15}$.

VirtuOHSU's core mission “is to provide outstanding leadership in education and training opportunities in surgical skills and simulation" ${ }^{15}$. By allowing surgical residents to train in a controlled space, VirtuOHSU aims to create measurable improvement in clinical performance, efficiency of healthcare, quality of care, and patient safety ${ }^{16}$. By requiring particular training courses to be completed by each resident, VirtuOHSU hopes to “eliminate technical skill acquisition by random opportunity by incorporating specific skills training into the five-year surgical education program" ${ }^{2}$ which ensures a uniform approach and higher quality of training for the residents ${ }^{14}$.

VirtuOHSU adopts the general philosophy that simulation-based learning should be part of continual medical education, ingrained throughout a physician's training ${ }^{1,3,8}$. VirtuOHSU allows for the development of skill sets prior to clinical experience with objective assessment and immediate feedback. Through structured, goal-orientated training and deliberate practice, skills can become understood, practiced, and automated by trainees ${ }^{1}$.

A key component of the simulation curriculum in VirtuOHSU is their focus on competency-based education. Originally, in the traditional apprenticeship-based model of surgical education, training was structured through time, or trial, based learning (i.e. number of cases performed). However, this model has proved to be a crude indicator of performance ability; alternatively, skill competency must be objectively quantified ${ }^{17}$. Competency-based education results in uniform skill performance and greater skill retention. In this model, residents are required to train in the specific skill until a certain benchmark (or proficiency 
standard) is reached. While VirtuOHSU trains surgeons in variety of surgical skills (open surgical techniques, endoscopy, ultrasound, vascular surgery, etc.), one area of their core curriculum involves the training of laparoscopic surgical techniques.

\section{LAPAROSCOPIC TRAINING \& CURRICULUM HISTORY AT OHSU}

Due to the fact that laparoscopy requires very specific manual skills, general surgery residents have had laparoscopic surgery training integrated into their simulation-based curriculum since 2008 when the doors of VirtuOHSU first opened. In fact, as of 2009 the American Board of Surgery (ABS) started to require passing a comprehensive laparoscopic skills examination prior to taking a General Surgery Qualifying Examination. This examination was formally titled the Fundamentals of Laparoscopic Surgery (FLS) program, which involved instruction and assessment of performance in the five manual tasks set forth by the McGill Inanimate System for Training and Evaluation of Laparoscopic Skills (MISTELS).

The five manual exercises are deconstructed tasks that require technical skills that can be directly carried over to operative performance techniques. For example, one task, peg transfer, is a task where the trainee must transfer six pegs from one side of a pegboard to the other, and then back to the original side. The learner must pick up the objects one-by-one using one instrument, transfer them to the instrument in the opposite hand, and then place the pegs on the opposite side of the pegboard. Once all six pegs are transferred to one side of the pegboard, the process is repeated in the opposite direction. This skill was designed to 
develop hand-eye coordination, visual-spatial perception, and non-dominate hand proficiency $^{18}$.

The laparoscopic simulation training in VirtuOHSU uses the MISTELS model to train each resident in fundamental laparoscopic skills during their time in the general surgery residency. The following description of the training comes directly from VirtuOHSU's Laparoscopic Skills Curriculum Overview:

"Learners will spend four two-hour sessions [once a year] focusing on topics in laparoscopy to include equipment set-up and trouble shooting, physiology, patient selection, and commonly performed procedures. Learners will also be instructed and mentored toward technical proficiency in the five essential tasks defined in the fundamentals of laparoscopic skills (FLS) curriculum." ${ }^{19}$

At the first training session, a performance pre-test of the five manual skills is directed after an introduction to the skills. The skills are then further practiced during weeks two and three and a final post-test is conducted during week four of the course. The time spent in the simulation lab will also be blocked off from a learner's clinical schedule, ensuring it as protected educational time. Additionally, learners have twenty-four hour access to the simulation lab in order to allow the opportunity for further practice. All of the above facets, as well as the utilization of many resources and experienced faculty members, reflect a significant investment in the education of surgical residents at OHSU.

In order to ensure quality control of education, a standard uniform curriculum for simulation training should exist across institutions ${ }^{3}$. However, as simulation-based training was established, there was not a clear development of standardized training curriculum for 
laparoscopic surgery. As OHSU's Department of Surgery started to expand their laparoscopic simulation-based training in 2008, a curriculum model establishing proficiency benchmarks for the psychomotor skills portion of the FLS program was adopted from the work of Drs. E. Matt Ritter and Daniel J. Scott. ${ }^{20}$ In their seminal paper establishing benchmarks for the FLS curriculum, Drs. Ritter and Scott, sought to establish structural validity to their proposed simulation-based training program. Since both physicians are experienced, fellowship-trained, laparoscopic surgeons, they were able to serve as expert subjects for their study. The goal of their work was to create a proficiency-based curriculum that would allow a trainee to not only successful complete the FLS manual skills exam, but also improve the trainee's operative performance ${ }^{20}$. "Before beginning this study, however, neither subject was extensively familiar with the FLS tasks and had spent no significant time practicing or training specifically with the FLS program"20. The subjects reviewed the FLS training supplies and performed each task a total of five times. The group mean performance times, excluding any values lying more than two standard deviations from the mean, were collected for each task. In order to make the benchmarks attainable for novice surgical residents, the proficiency benchmarks were set two standard deviations above the mean for four of the five tasks (peg transfer being excluded) ${ }^{20}$. A summary of these results, taken from their paper, is shown in Figure 1.

Figure 1

\begin{tabular}{|c|c|c|c|c|c|}
\hline \multirow[b]{2}{*}{ Task } & \multicolumn{5}{|c|}{ Performance-Based Proficiency Levels } \\
\hline & Task Name & Proficiency Level & Time (s) & Allowable Errors & Repetitions \\
\hline 1 & Peg transfer & Mean & 48 & No drops outside field of view & $\begin{array}{l}2 \text { consecutive }+ \\
10 \text { nonconsecutive }\end{array}$ \\
\hline 2 & Pattern cut & Mean +2 SD & 98 & All cuts within $2 \mathrm{~mm}$ of line & 2 consecutive \\
\hline 3 & Ligating loop & Mean +2 SD & 53 & $\begin{array}{l}\text { Up to } 1-\mathrm{mm} \text { accuracy error } \\
\text { allowed. Knot must be secure. }\end{array}$ & 2 consecutive \\
\hline 4 & Extracorporeal suture & Mean +2 SD & 136 & $\begin{array}{l}\text { Up to } 1-\mathrm{mm} \text { accuracy error } \\
\text { allowed. Knot must be secure. }\end{array}$ & 2 consecutive \\
\hline 5 & Intracorporeal suture & Mean +2 SD & 112 & $\begin{array}{l}\text { Up to } 1-\mathrm{mm} \text { accuracy error } \\
\text { allowed. Knot must be secure. }\end{array}$ & $\begin{array}{l}2 \text { consecutive }+ \\
10 \text { nonconsecutive }\end{array}$ \\
\hline
\end{tabular}




\section{OHSU LAPAROSCOPIC TRAINING DATA EVALUATION}

While performance documentation existed for the OHSU general surgery

residents, it had not been organized or examined prior to the work done by my co-volunteer, William Coad, and myself. All FLS skills performance data from the OHSU general surgery residents over the past six years $(2008$ - 2014) was organized by the year in which each resident matriculated into the program. Their results were examined for each year they were involved in the residency (program year, PGY).

I first wanted to examine the effectiveness of VirtuOHSU's training model. To look at this factor, I decided to look at the percent improvement of each resident for each task during each respective program year number, the percent improvement for their normalized MISTEL score, as well as their percent improvement from their intern year to their fourth residency year. Figure 2 summarizes the results.

Figure 2

\begin{tabular}{|l|l|l|r|r|r|}
\hline \multicolumn{1}{|c|}{ Task } & PGY 1 & PGY 2 & PGY 3 & PGY 4 & PGY 1 - PGY 4 \\
\hline Peg transfer & $27.90 \%$ & $13.59 \%$ & $7.60 \%$ & $7.13 \%$ & $16.07 \%$ \\
\hline Pattern cut & $33.10 \%$ & $10.45 \%$ & $21.56 \%$ & $12.38 \%$ & $33.71 \%$ \\
\hline Ligating loop & $25.94 \%$ & $18.62 \%$ & $13.62 \%$ & $39.03 \%$ & $47.91 \%$ \\
\hline Extracorporeal suture & $26.09 \%$ & $18.70 \%$ & $5.97 \%$ & $0.36 \%$ & $30.67 \%$ \\
\hline Intracorporeal suture & $37.83 \%$ & $24.14 \%$ & $21.72 \%$ & $17.38 \%$ & $29.42 \%$ \\
\hline Normalized MISTEL Score & $52.65 \%$ & $17.77 \%$ & $7.36 \%$ & $3.59 \%$ & $16.33 \%$ \\
\hline
\end{tabular}

It can be seen that for each task (on average) the residents significantly improved between their pre and post tests. The data also shows that for the majority of the tasks (excluding ligating loop) the greatest improvement happens during their first (intern) year and tends to decline as they progress through their residency; this was to be expected and may be attributed to the fact that the greatest learning occurs after initial introduction to a 
skill and thus the learning curve for skill improvement is not linear or exponential. For each task and their normalized MISTEL score, the residents significantly improved between their first and fourth year in the program. This data is encouraging to suggest that OHSU's training practices (proficiency-based training, guided instruction, 4 2-hour sessions, etc.) are training the residents to become more adept surgeons, and agrees with many other studies that have demonstrated residents show significant improvement of laparoscopic skills using simulation $^{21,22}$. However, my main area of concern was surrounding whether or not the benchmarks used (adopted from the work of Drs. Ritter and Scott) were still relevant to VirtuOHSU's training curriculum as the program has matured.

The next step was to look at how our residents were performing compared to the proficiency benchmarks set by the FLS examination as well as the OHSU benchmarks as adopted from the work of Drs. Ritter and Scott. The following scatter plots (Figures 3-8) visually display the findings for each task as well as each residents' normalized MISTEL score. Each data point on the graph represents a single learner's performance (in seconds) for the given task per program year relative to the defined proficiency standards.

Figure 3

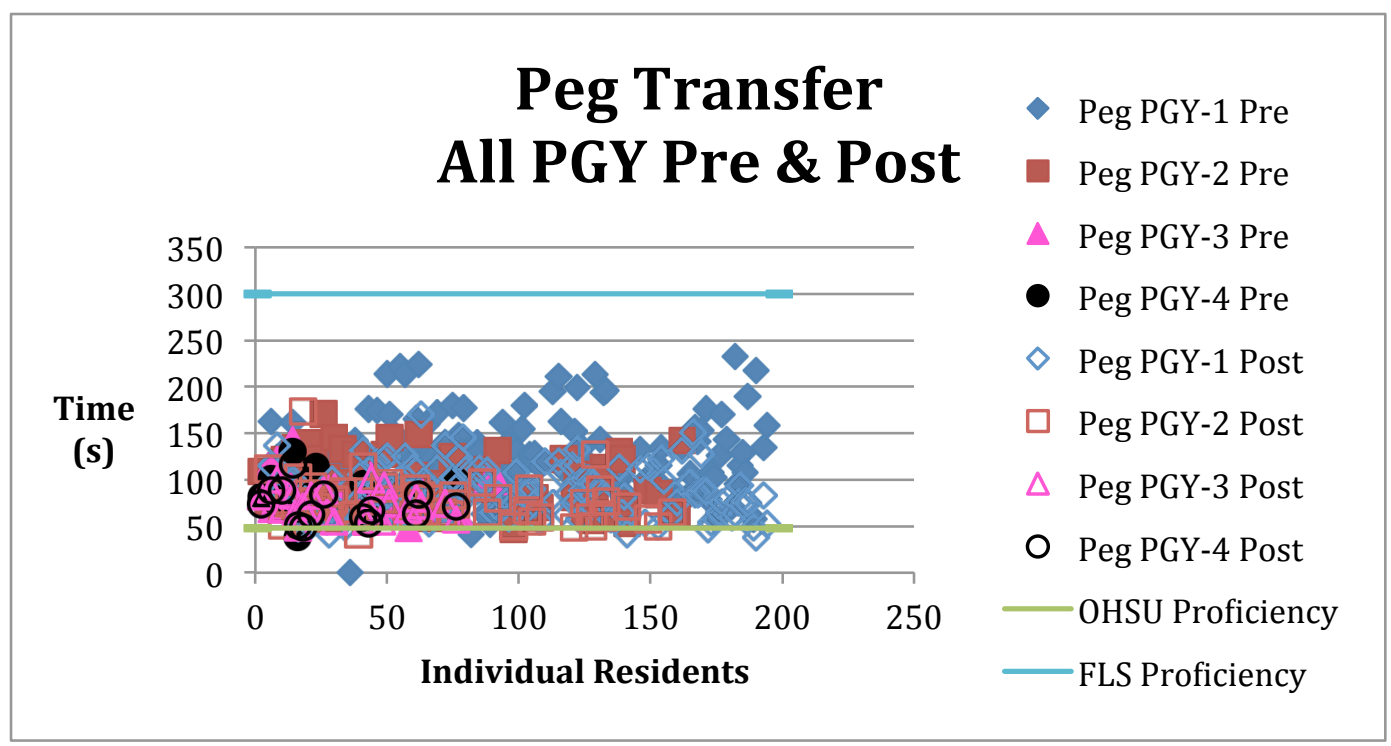


Figure 4

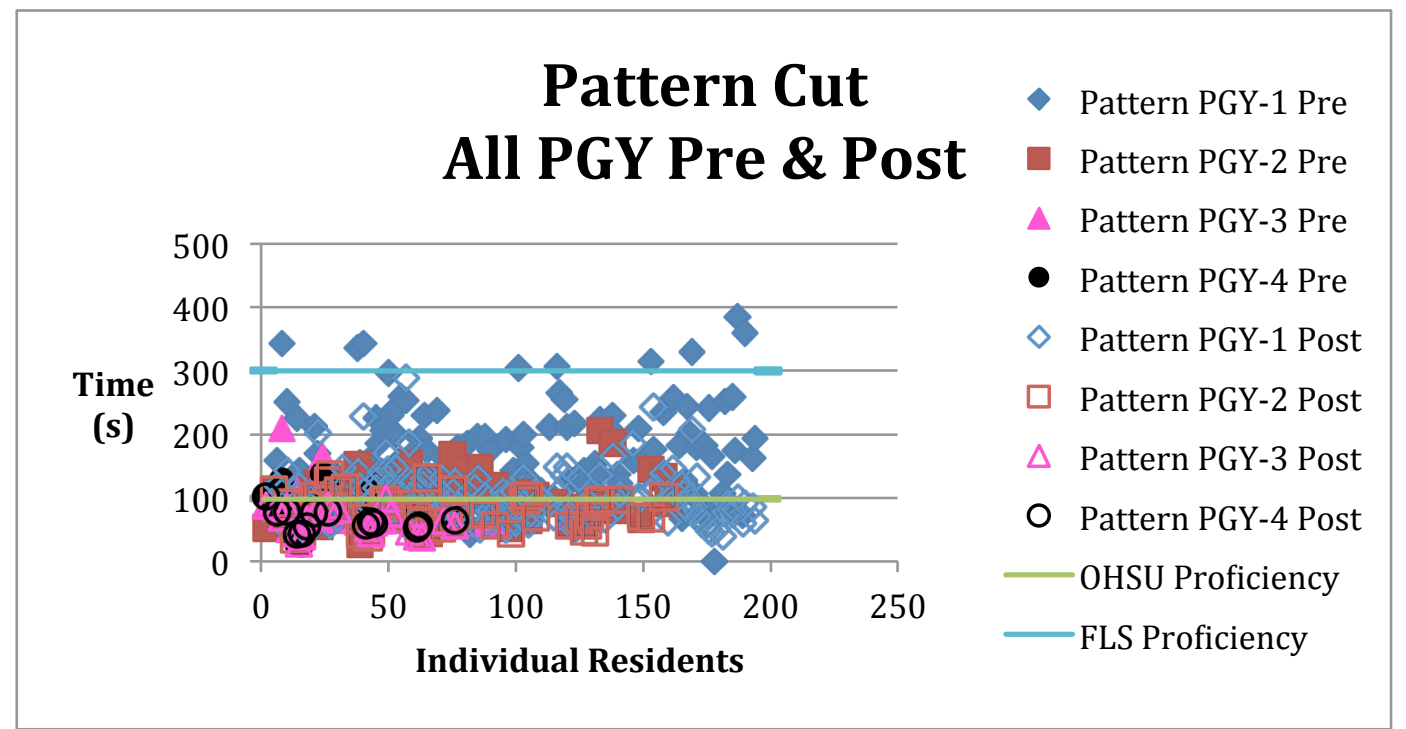

Figure 5

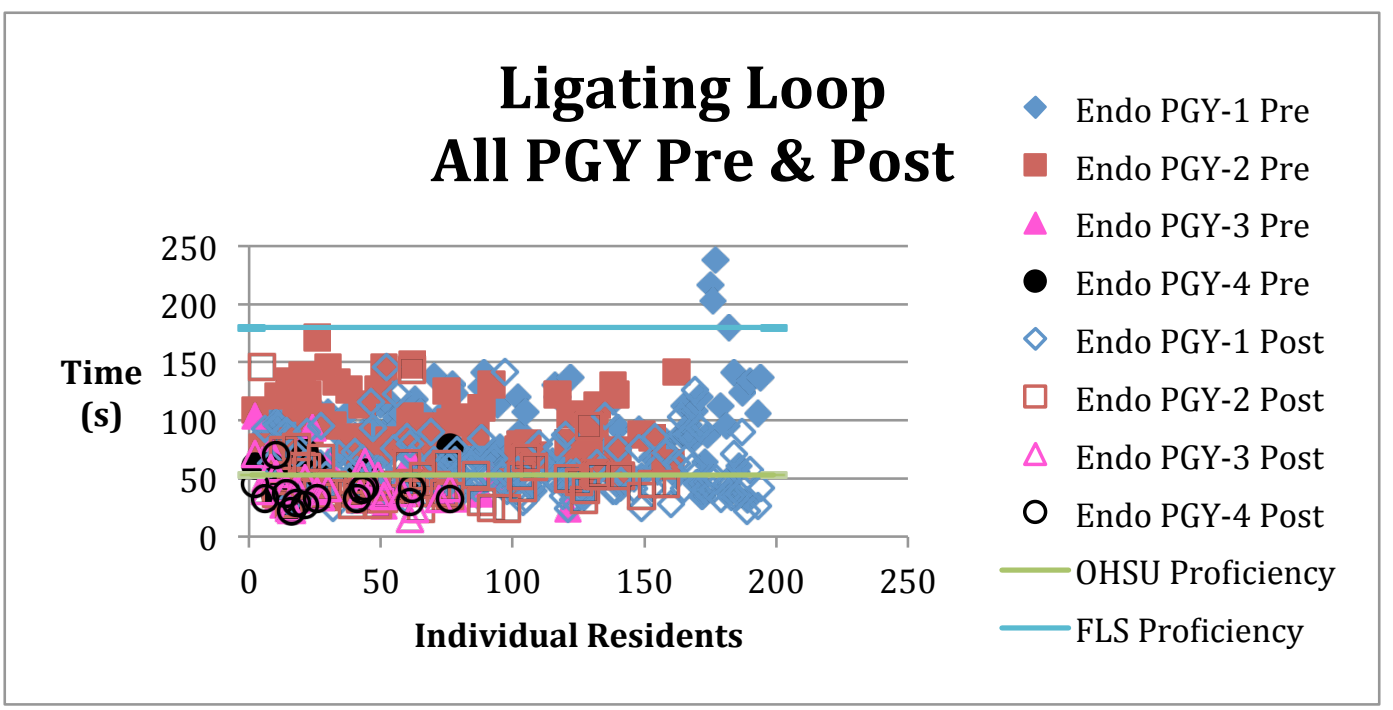

Figure 6

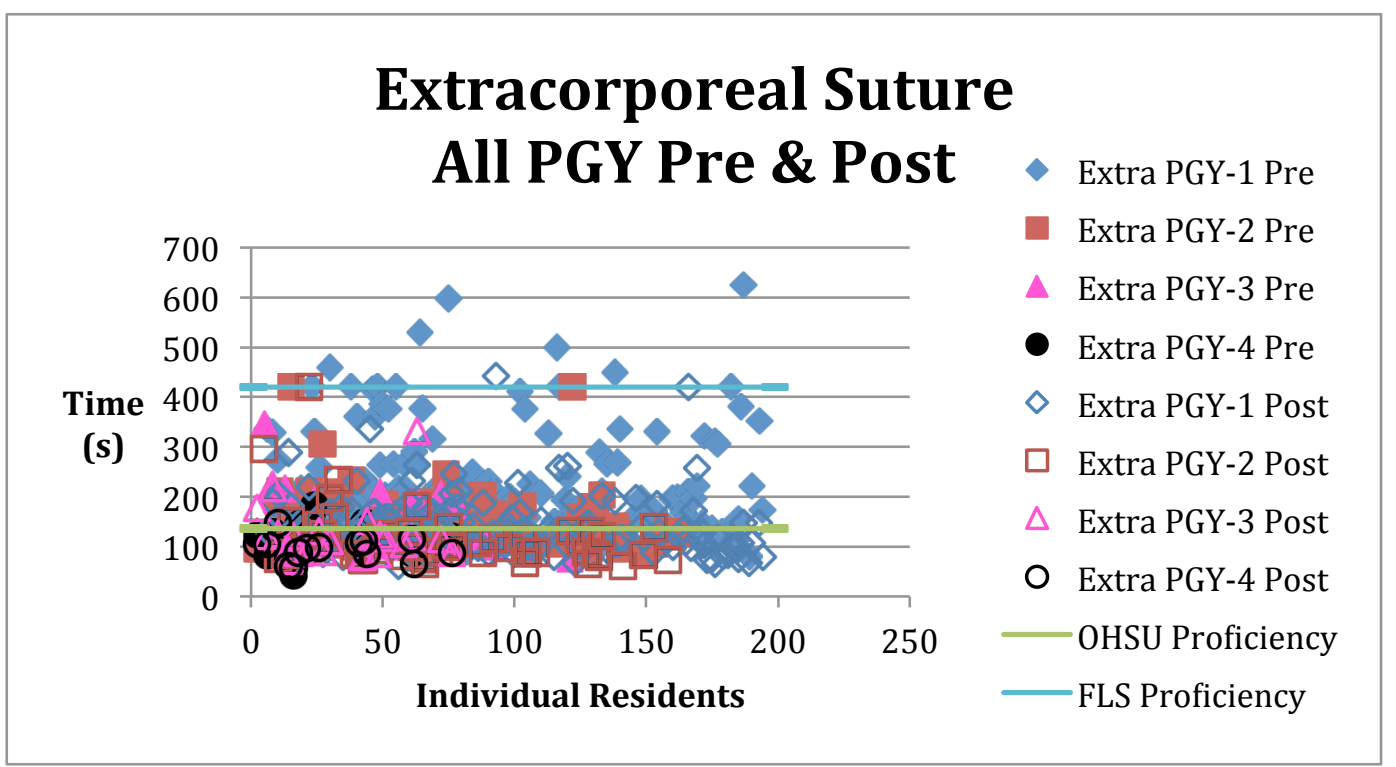


Figure 7

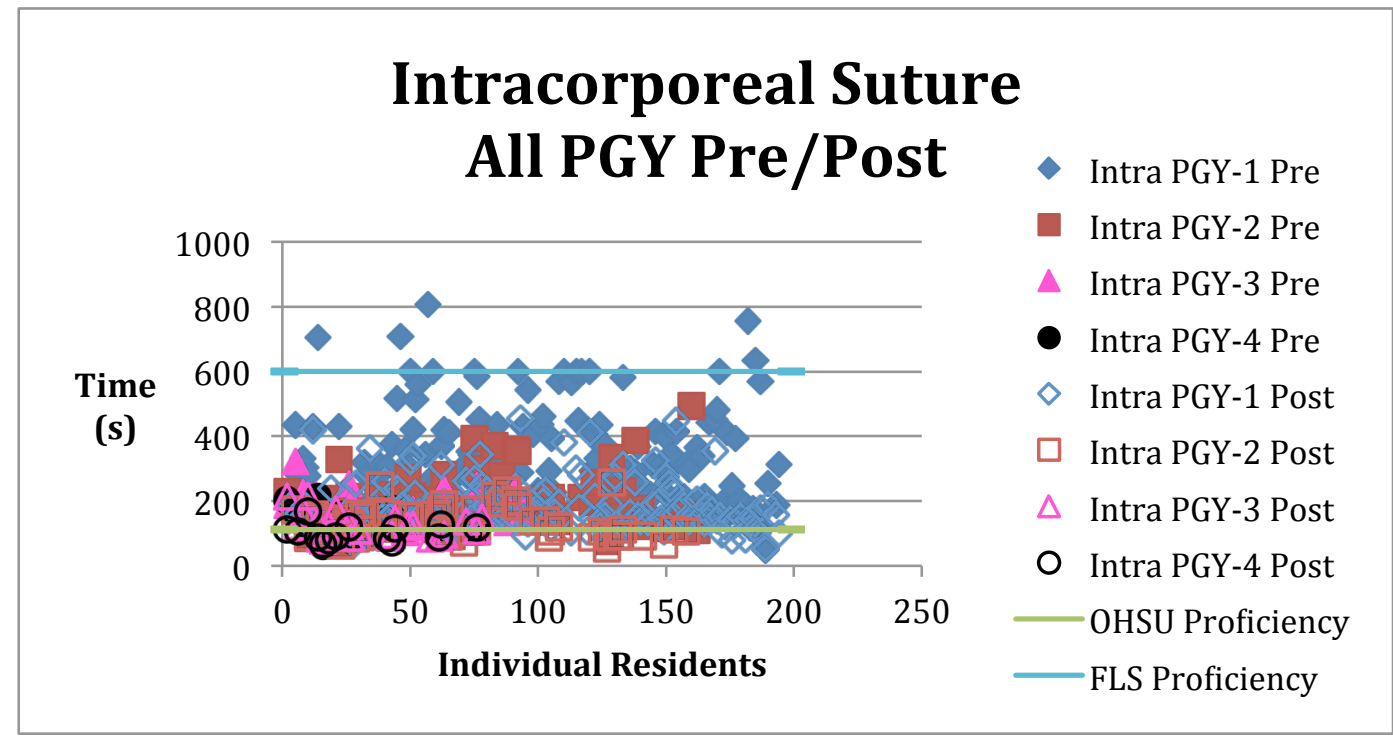

Figure 8

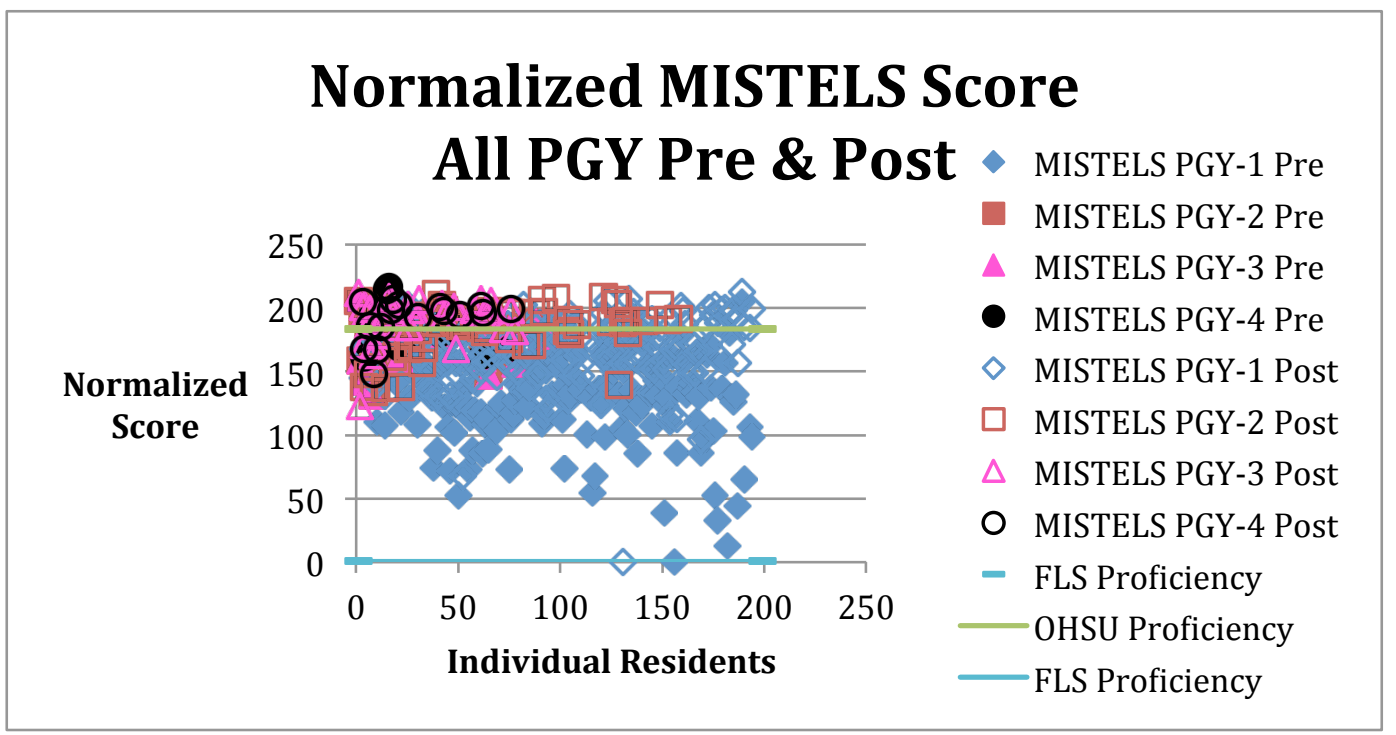

Figures $3-8$ clearly show that while the majority of residents over the past six years are meeting the FLS proficiency benchmarks, many of them are not meeting the standards set by Drs. Ritter and Scott that were adopted by OHSU. This point is further demonstrated by Figure 9, which details the percentage of residents (by program year number) who met the FLS benchmarks, OHSU benchmarks, and the difference between these two quantities. 
Figure 9

\begin{tabular}{|c|c|c|c|c|}
\hline Task & PGY & Met FLS Benchmarks & Met OHSU Benchmarks & Difference \\
\hline \multirow[t]{4}{*}{ Peg Transfer } & PGY 1 & $100 \%$ & $4 \%$ & $96 \%$ \\
\hline & PGY 2 & $100 \%$ & $4 \%$ & $96 \%$ \\
\hline & PGY 3 & $100 \%$ & $0 \%$ & $100 \%$ \\
\hline & PGY 4 & $100 \%$ & $0 \%$ & $100 \%$ \\
\hline \multirow{4}{*}{$\begin{array}{l}\text { Precision } \\
\text { Cutting }\end{array}$} & PGY 1 & $100 \%$ & $50 \%$ & $50 \%$ \\
\hline & PGY 2 & $100 \%$ & $78 \%$ & $22 \%$ \\
\hline & PGY 3 & $100 \%$ & $96 \%$ & $4 \%$ \\
\hline & PGY 4 & $100 \%$ & $93 \%$ & $7 \%$ \\
\hline \multirow[t]{4}{*}{ Ligating Loop } & PGY 1 & $100 \%$ & $54 \%$ & $46 \%$ \\
\hline & PGY 2 & $100 \%$ & $76 \%$ & $24 \%$ \\
\hline & PGY 3 & $100 \%$ & $83 \%$ & $17 \%$ \\
\hline & PGY 4 & $100 \%$ & $93 \%$ & $7 \%$ \\
\hline \multirow{4}{*}{$\begin{array}{l}\text { Extracorporeal } \\
\text { Knot }\end{array}$} & PGY 1 & $99 \%$ & $60 \%$ & $39 \%$ \\
\hline & PGY 2 & $100 \%$ & $82 \%$ & $18 \%$ \\
\hline & PGY 3 & $100 \%$ & $83 \%$ & $17 \%$ \\
\hline & PGY 4 & $100 \%$ & $93 \%$ & $7 \%$ \\
\hline \multirow{4}{*}{$\begin{array}{l}\text { Intracorporeal } \\
\text { Knot }\end{array}$} & PGY 1 & $100 \%$ & $14 \%$ & $86 \%$ \\
\hline & PGY 2 & $100 \%$ & $43 \%$ & $57 \%$ \\
\hline & PGY 3 & $100 \%$ & $46 \%$ & $54 \%$ \\
\hline & PGY 4 & $100 \%$ & $57 \%$ & $43 \%$ \\
\hline \multirow{4}{*}{$\begin{array}{l}\text { Normalized } \\
\text { MISTELS } \\
\text { Score }\end{array}$} & PGY 1 & $100 \%$ & $33 \%$ & $67 \%$ \\
\hline & PGY 2 & $100 \%$ & $66 \%$ & $34 \%$ \\
\hline & PGY 3 & $100 \%$ & $79 \%$ & $21 \%$ \\
\hline & PGY 4 & $100 \%$ & $83 \%$ & $17 \%$ \\
\hline
\end{tabular}

This large discrepancy between the OHSU standards and the FLS standards, as well as the amount of residents not attaining the OHSU standards, was the catalyst for me becoming interested in the validity of the laparoscopic training benchmarks used by OHSU.

While virtually all residents are meeting the standards set forth by the FLS program, it is felt by many laparoscopists that the proficiency benchmarks defined by the FLS program do not sufficiently correlate with optimal operative performance, and thus there is a need for more demanding proficiency standards such as the model proposed by Drs. Ritter and Scott. 
However, it can clearly be seen that many residents are not able to attain those standards. Since Drs. Ritter and Scott's paper, there has been a significant gap in the discourse's understanding of what proficiency metric is considered adequate for laparoscopic surgery simulation-based training; while the model from Drs. Ritter and Scott served as a satisfactory starting mark for the Department of Surgery's newly expanding simulation effort in 2008, the data collected from VirtuOHSU's training program suggests a need to adjust the current curriculum to reflect the actual laparoscopic skills performance from general surgery residents over the past six years. A natural conclusion might be to say that the current proficiency standards are adequate and all that is needed is to push the residents to perform stronger and meet the current benchmarks. However, I believe there is fallacy in this argument. When the training model for laparoscopic surgical skills at OHSU was adopted, it was adopted from a study where the benchmarks were defined arbitrarily. VirtuOHSU's preexisting curriculum model for laparoscopic MISTELS tasks sets proficiency time benchmarks based on the work of two experienced, fellowship-trained surgeons at a different institution with adjustment for novice performance set randomly at two standard deviations above the mean time performance, due to the assumption that experienced surgeons are able to perform the tasks faster than novice learners. The work in this paper, on the other hand, proposes benchmarks for the OHSU Department of Surgery based directly on the performance of 194 residents in the OHSU General Surgery Residency program (the second largest general surgery residency program in the United States) over the past six years. Furthermore, as a research volunteer in VirtuOHSU over the last eighteen months, I have seen that it is not realistic to expect an intern-year surgeon to perform up to the same standard as a fourth-year resident as the 
current curriculum model requires. True novices may become frustrated, discouraged, and lose confidence due to these unrealistic expectations. If these beginning learners are held to the same standards as their senior peers, bad habits may develop in order to reach the prescribed time metrics. These bad habits may the later result in undesirable operative techniques in the actual clinical environment. Thus, it is important to set attainable proficiency standards for each program year level to ensure effective surgical education.

\section{OHSU LAPAROSCOPIC TRAINING RECOMMENDATIONS}

The goal of my thesis is to objectify what is now subjective. Starting in July 2014, the OHSU Department of Surgery will implement the ACGME Milestones Project into their general surgery residency program. The aim of this program is to "develop measurable milestones to use as a metric of resident accomplishment and program educational effectiveness" 23 . The Milestones Project also aims to set benchmarks to be attained by residents within a specific program year. As the Department of Surgery enacts the ACGME Milestones Project it will be necessary to determine what are acceptable proficiency standards for laparoscopic surgery training. The work of this paper strives to set realistic and defined laparoscopic proficiency benchmarks for residents during their first, second, third, and fourth program year by examining how 194 residents performed during each respective year of their residency. These benchmarks could be fully integrated into the OHSU Milestones Project.

All FLS skills performance data from the OHSU general surgery residents over the past six years $(2008$ - 2014) was organized by the year in which each resident matriculated 
into the program and their results were examined for each year they were involved in the residency. While the proficiency levels set by Drs. Ritter and Scott were a good staring mark, moving forward, they are no longer applicable to OHSU's laparoscopic simulation curriculum due to the fact that significant data has been collected to postulate more concrete, and attainable, benchmarks. For each program year that had laparoscopic simulation data for the 194 residents, the group mean performance times, excluding any values lying more than two standard deviations from the mean (to exclude any significant outliers), were collected for each task. The results are shown in Figure 10.

Figure 10

\begin{tabular}{|l|l|r|r|}
\hline \multirow{4}{*}{ Skill } & Program Year & Proficiency Time $(s)$ & Number of Residents \\
\hline \multirow{5}{*}{ Peg Transfer } & PGY 1 & 84 & 134 \\
\cline { 2 - 4 } & PGY 2 & 73 & 54 \\
\cline { 2 - 4 } & PGY 3 & 74 & 24 \\
\cline { 2 - 4 } & PGY 4 & 69 & 13 \\
\hline \multirow{5}{*}{ Precision Cutting } & PGY 1 & 95 & 131 \\
\cline { 2 - 4 } & PGY 2 & 76 & 53 \\
\cline { 2 - 4 } & PGY 3 & 64 & 23 \\
\cline { 2 - 4 } & PGY 4 & 62 & 13 \\
\hline \multirow{5}{*}{ Extracorporeal Knot Loop } & PGY 1 & 55 & 127 \\
\cline { 2 - 4 } & PGY 2 & 45 & 53 \\
\cline { 2 - 4 } & PGY 3 & 40 & 22 \\
\cline { 2 - 4 } & PGY 4 & 34 & 13 \\
\cline { 2 - 4 } & PGY 1 & 135 & 134 \\
\cline { 2 - 4 } & PGY 2 & 104 & 53 \\
\cline { 2 - 4 } & PGY 4 & 114 & 22 \\
\hline Intracorporeal Knot & PGY 1 & 91 & 13 \\
\cline { 2 - 5 } & PGY 2 & 165 & 153 \\
\cline { 2 - 5 } & PGY 3 & 125 & 55 \\
\cline { 2 - 5 } & PGY 4 & 116 & 13 \\
\hline
\end{tabular}

Guided by the data from Figure 10, new proposed proficiency levels were created. In creation of these new benchmarks, data was not pulled directly from Figure 10 in order to 
ensure performance improvement at each PGY level. Rather, the difference was taken between the average performance time of a PGY 1 and PGY 4 resident. This number was then divided by three to determine how much improvement time was needed for a PGY 4 resident to achieve the desired end result over the course of four years. For example, in the peg transfer task the average PGY 1 resident was able to perform the skill in 84 seconds. This time was subtracted from the average time that a PGY 4 resident was able to complete the task (69 seconds), giving a value of 15 seconds. Dividing by three yields an average year-toyear improvement of 5 seconds. Thus a PGY 1, PGY 2, PGY 3, and PGY 4 resident should be able to complete the peg transfer task in $84,79,74$, and 69 seconds respectively. The complete breakdown of the new proposed proficiency benchmarks are shown in Figure 11.

Figure 11

\begin{tabular}{|c|c|c|}
\hline Skill & Program Year & Proficiency Time (s) \\
\hline \multirow{4}{*}{ Peg Transfer } & PGY 1 & 84 \\
\hline & PGY 2 & 79 \\
\hline & PGY 3 & 74 \\
\hline & PGY 4 & 69 \\
\hline \multirow[t]{4}{*}{ Precision Cutting } & PGY 1 & 95 \\
\hline & PGY 2 & 84 \\
\hline & PGY 3 & 73 \\
\hline & PGY 4 & 62 \\
\hline \multirow[t]{4}{*}{ Ligating Loop } & PGY 1 & 55 \\
\hline & PGY 2 & 48 \\
\hline & PGY 3 & 41 \\
\hline & PGY 4 & 34 \\
\hline \multirow[t]{4}{*}{ Extracorporeal Knot } & PGY 1 & 135 \\
\hline & PGY 2 & 120 \\
\hline & PGY 3 & 106 \\
\hline & PGY 4 & 91 \\
\hline \multirow[t]{4}{*}{ Intracorporeal Knot } & PGY 1 & 165 \\
\hline & PGY 2 & 142 \\
\hline & PGY 3 & 120 \\
\hline & PGY 4 & 97 \\
\hline
\end{tabular}


While these times differ from the levels set by Drs. Scott and Ritter, the new proposed proficiency times show, objectively, to what level OHSU residents have been preforming over the past six years and to what level future residents can be expected to perform under the preexisting training model. Considering these levels have shown to be attainable for residents of their specific level, these benchmarks would be appropriate levels moving forward with OHSU's Milestones Project.

\section{SUMMARY}

As the second largest general surgery residency program in the nation, OHSU serves as an ideal case study for examining several facets of general surgery resident education. As medical education evolves, it has experienced many unique challenges. One answer to some of these challenges has been the integration of simulation-based training. In 2008, OHSU made a significant investment in their simulation-based training program by opening a surgical skills lab, VirtuOHSU, which has led OHSU to be recognized as a nationally recognized simulation institute. The laparoscopic skills training course offered at VirtuOHSU is one of the most mature and developed simulation-based programs, which operates under an educational philosophy of proficiency-based training. When VirtuOHSU started training general surgery residents in laparoscopic skills, a proficiency-based model for laparoscopic skills was adopted from the work of Drs. E. Matt Ritter and Daniel J. Scott, two experienced laparoscopic surgeons. While this work was a good starting point for VirtuOHSU, current data analysis suggests that the trainees at OHSU are not meeting the standards set by Drs. Ritter and Scott. Thus, the standards are not adequate due to the fact 
that the current proficiency benchmarks do not reflect actual resident performance. The goal of this paper was to propose more applicable proficiency standards, based on performance data from OHSU general surgery residents over the past six years, in order to ensure effective surgical education in the future.

\section{FUTURE DIRECTIONS}

While the outliers were excluded from the data analysis of this project to obtain more homogeneous results, I believe that there is much interest surrounding these high and low performers; it is worthwhile to attempt identifying commonalities that separate the high and low performers from those residents who performed averagely in the laparoscopic simulation skills lab. Furthermore, it is worthwhile to examine if performance in the simulation lab correlates to performance in the operating room. Subjectively, VirtuOHSU feels that the simulation skills lab contributes much to a resident's educational experience, including operative performance; however the future of this study aims to objectively examine the correlation between surgical skills lab experience and a trainee's actual operative performance. This will be the next stage of the project.

This endeavor will consist of three components. First, in order to examine what separates a high performer from a low performer, all residents (high, low, and average performers) will be sent a survey focused on their past education and training, personal history, their opinions surrounding simulation training, and their laparoscopic simulation and operative performance. The questions are listed in Figure 12. 
Figure 12

\begin{tabular}{|l|l|}
\hline \multicolumn{2}{|l|}{ Survey Questions } \\
\hline 1 & What is your name? \\
\hline 2 & Where did you go to medical school? \\
\hline 3 & When was your intern year at OHSU? \\
\hline 4 & What residency program are you in? \\
\hline 5 & If general surgery, what is your intended specialty? \\
\hline 6 & Are you left or right handed? \\
\hline 7 & How would you rate your proficiency with your non-dominate hand? \\
\hline 8 & Have you ever played musical instruments? \\
\hline 10 & Do you have any experience or history playing video games? \\
\hline 11 & Did you have access to a skills lab prior to the beginning of your residency? \\
\hline 12 & If so, did you participate in a formal class or bootcamp for laparoscopic skills? \\
\hline 13 & $\begin{array}{l}\text { Assuming a laparoscopic skills course is } 8 \text { hours total (4 2-hour sessions) how many } \\
\text { hours total did you spend in the skills lab? }\end{array}$ \\
\hline 14 & Did you practice laparoscopic skills on your own time outside of a structured course? \\
\hline 15 & $\begin{array}{l}\text { If so, how often have you spent time in a laparoscopic skills lab outside of a structured } \\
\text { course? }\end{array}$ \\
\hline 16 & What were your barriers to practicing? \\
\hline 17 & $\begin{array}{l}\text { Do you think performance in a laparoscopic skills lab correlates to operative } \\
\text { performance? }\end{array}$ \\
\hline 18 & $\begin{array}{l}\text { Has time spent in the laparoscopic skills lab improved your operative performance } \\
\text { during laparoscopic cases? }\end{array}$ \\
\hline 19 & How would you rate your laparoscopic proficiency in the operating room? \\
\hline 20 & $\begin{array}{l}\text { Should PGY Level advancement be linked to performance in the skills lab through the } \\
\text { ACGME Milestones Project? }\end{array}$ \\
\hline 21 & $\begin{array}{l}\text { Have you received specific feedback on your laparoscopic skills in either the skills lab or } \\
\text { operating room? }\end{array}$ \\
\hline 22 & Have you taken the FLS exam? \\
\hline 23 & If so, did you pass the FLS exam? \\
\hline
\end{tabular}

Preliminary data has shown that the majority of residents report not having access to a skills

lab prior to the beginning of their residency, spending additional time in the laparoscopic

skills lab outside of a structured course, believing that skills lab performance correlates to operative performance, and that their time in the skills lab has improved their operative performance. Second, the residents' operative case logs will be examined to look at their 
operative history, specifically the laparoscopic cases they have been involved with. Third, the residents' operative performance assessments for laparoscopic cases will be analyzed to see how each resident is actually performing in the operating room.

By examining the data from these three components (surveys, operative case logs, and operative performance assessments), I hope to examine three facets of laparoscopic surgical education. I am curious if common factors exist amongst residents who are high and low performers in the simulation lab, how operative history relates to their performance in the skills lab, and whether or not a correlation exists between performance in the simulation lab and performance in the operating room.

\section{FINAL STATEMENTS}

Considering that the ACGME Milestones Project attempts to set benchmarks to be attained by residents at a particular point during their residency, the suggestion presented in this paper fits well within the curriculum adjustment OHSU is implementing in July 2014. If the future research described in this paper identifies a correlation between skills lab performance and operative performance, I believe program year advancement in the OHSU general surgery residency should be linked to performance in the skills lab using the benchmarks I have proposed. The overreaching goal of the ACGME Milestones project is to set defined expectations for surgical residency programs and the residents they serve; by adopting this new, attainable, and validated model, OHSU would be implementing a standard curriculum that would maximize training efficiency and educational benefit ${ }^{3}$. By requiring residents to meet clearly defined performance expectations, residents will be held 
accountable to these set proficiency benchmarks. The future of the simulation skills lab will be treated as an additional mandatory educational requirement, rather than its current position as a tool that simply furthers a resident's educational experience. As VirtuOHSU and the laparoscopic simulation program continue to mature, this shift in perspective may require a later reevaluation of the proficiency standards yet again due to an increase in overall resident performance.

Further validation of this training paradigm may also have far reaching implications for other institutions. Due to the fact that OHSU trains the second largest amount of general surgery residents per year in the country, the data obtained in this study may be sufficient enough to set the standard for the next generation of the FLS program training. Going forward, the methods and approaches presented in this paper could be applied to a multiple-institution study to examine the overall proficiency standards of laparoscopic simulation-based training across the country. 
${ }^{1}$ Kolozsvari NO, Feldman LS, Vassiliou MC, et all. Sim One, Do One Teach One:

Considerations in Designing Training Curricula for Surgical Simulation. Journal of Surgical Education. 2011;68;5:421-427.

${ }^{2}$ Spight D. The End of "See One, Do One, Teach One": Incorporating Simulation into Surgical Skills Education at OHSU and Beyond. Oregon Health and Science University. 2011.

${ }^{3}$ Korndorffer JR, Stefanidis D, Scott DJ. Laparoscopic Skill Laboratories: Current Assessment and A Call for Resident Training Standards. The American Journal of Surgery. 2006;191:17-22.

${ }^{4}$ To Err Is Human: Building A Safer Health System. U.S. Institute of Medicine. 1999.

${ }^{5}$ Bridges M, Diamond DL. The Financial Impact of Teaching Surgical Residents in the Operating Room. American Journal of Surgery. 1999;177;38-32.

${ }^{6}$ Chen PW. Are Today's New Surgeons Unprepared? New York Times. 2013.

${ }^{7}$ Carmichael M. Hidden Risks; Rare but Often Serious Complications Continue to Plague the Most Common Laparoscopic Operation. Newsweek. 2007

${ }^{8}$ Bashankaev B, Baido S, Wexner S. Review of Available Methods of Simulation Training to Facilitate Surgical Education. Surgical Endoscopy. 2011;25:28-35.

${ }^{9}$ Creating a Path for Healthcare Simulation in Arizona. Arizona Hospital and Healthcare Association. 2007.

${ }^{10}$ Brindley PG, Jones DB, Grantcharov T, et all. Surgical Simulation: The Solution to Safe Training or a Promise Unfulfilled? Canadian Association of University Surgeons' Annual Symposium. Canadian Medical Association. 2012;55:200-206. 
${ }^{11}$ Satava RM. Virtual Reality Surgical Simulator: The First Steps. Surgical Endoscopy. $1993 ; 7: 203-205$.

${ }^{12}$ Surgical Simulation for Training: Skills Transfer to the Operating Room. Australian Safety and Efficacy Register of New Interventional Procedures - Surgical. 2007.

${ }^{13}$ Tavakol M, Mohagheghi MA, Dennick R. Assessing the Skills of Surgical Residents Using Simulation. Journals of Surgical Education. 2008;65;2: 77-83.

${ }^{14}$ Satava RM. Emerging Trends that Herald the Future of Surgical Simulation. Surgical Clinics of North America. 2010;90:623-633.

${ }^{15}$ VirtuOHSU. Oregon Health and Science University. Web.

${ }^{16}$ Spight D. VirtuOHSU Surgical Simulation Lab. Oregon Health and Science University. 2012.

${ }^{17}$ Choy I, Okraineec A. Simulation in Surgery: Perfecting the Practice. Surgical Clinics of North America. 2010;90:457-473.

${ }^{18}$ FLS Manual Skills Written Instructions and Performance Guidelines. Fundamentals of Laparoscopic Surgery. 2014.

${ }^{19}$ Spight D. Laparoscopic Skills Curriculum. VirtuOHSU. 2009;1-35.

${ }^{20}$ Ritter EM, Scott DJ. Design of a Proficiency-Based Skills Training Curriculum for the Fundamentals of Laparoscopic Surgery. SAGE Surgical Innovation. 2007;14;2:107-112.

${ }^{21}$ Scott DJ, Bergen PC, Rege RV, et al. Laparoscopic Training on Bench Models: Better and More Cost Effective than Operating Room Experience? Journal of the American College of Surgeons. 2000;191:272-283. 
${ }^{22}$ Scott DJ, Young WN, Tesfay ST, et al. Laparoscopic Skills Training. American Journal of Surgery. 2001;192:137-142.

${ }^{23}$ ACGME Milestones Project. OHSU Department of Surgery. 2014. 